\title{
The Elevation in Preoperative Procalcitonin Is Associated with a Poor Prognosis for Patients Undergoing Resection for Colorectal Cancer
}

\author{
Toru Miyake $^{a}$ Hiroya lida $^{\mathrm{a}}$ Tomoharu Shimizu $^{\mathrm{b}}$ Tomoyuki Ueki ${ }^{\mathrm{a}}$ \\ Masatsugu Kojima ${ }^{a}$ Hiroyuki Ohta ${ }^{c}$ Tsuyoshi Yamaguchi ${ }^{a}$ Sachiko Kaida ${ }^{a}$ \\ Eiji Mekatac ${ }^{c}$ Yoshihiro Endo $^{d}$ Masaji Tani $^{a}$ \\ aDepartment of Surgery, Shiga University of Medical Science, Shiga, Japan; b Medical Safety Section, Shiga University \\ of Medical Science Hospital, Shiga, Japan; 'Department of Comprehensive Surgery, Shiga University of Medical \\ Science, Shiga, Japan; 'Department of Clinical Nursing, Shiga University of Medical Science, Shiga, Japan
}

\section{Keywords}

Procalcitonin · Sepsis · Infection · mGPS · Prognostic nutritional index

\section{Abstract \\ Background: Procalcitonin (PCT) is a well-known marker for bacterial infection; however, the clinical significance of PCT in the long-term prognosis after colorectal cancer (CRC) sur- gery remains unclear. Methods: This is a retrospective review of 277 patients that underwent CRC surgery to investigate the relationship between preoperative PCT, clinicopatho- logical condition, cancer-specific overall survival (OS), and relapse-free survival (RFS). Results: Median follow-up inter- val was 5.0 years in all patients. Thirty-six patients developed recurrence, and 46 patients died due to recurrences or me- tastases of CRC. Preoperative PCT levels were highest in Stage IV patients. The cancer-specific OS in patients with Stage IV/PCT $\leq 0.05 \mathrm{ng} / \mathrm{mL}$ was significantly higher than those with Stage IV/PCT $>0.05 \mathrm{ng} / \mathrm{mL}$ ( 3 years survival; 42.3 vs. $14.3 \%, p=0.0413)$. On multivariate analysis, gender, TNM classification, and PCT were identified as significant risk fac-}

karger@karger.com www.karger.com/dsu

Karger ${ }^{\prime \prime} \div$

BOPEN ACCESS
(C) 2020 The Author(s)

Published by S. Karger AG, Basel

This is an Open Access article licensed under the Creative Commons Attribution-NonCommercial-4.0 International License (CC BY-NC) (http://www.karger.com/Services/OpenAccessLicense), applicable to the online version of the article only. Usage and distribution for commercial purposes requires written permission. tors for cancer-specific OS in patients with Stage I-III CRC. The cancer-specific OS rate of these patients with PCT $\geq 0.08$ $\mathrm{ng} / \mathrm{mL}$, compared with $\mathrm{PCT}<0.08 \mathrm{ng} / \mathrm{mL}$, was significantly decreased (5 years survival; 59.1 vs. $92.7 \%, p<0.0001$ ). TNM classification was finally identified as an independent risk factor for cancer-specific RFS in these patients by multivariate analysis. Conclusion: High preoperative PCT values in CRC patients appeared to be associated with poor OS but not RFS following surgical treatments.

(C) 2020 The Author(s)

Published by S. Karger AG, Basel

\section{Introduction}

Colorectal cancer (CRC) is the third most common cancer worldwide. Despite the development of new chemotherapy regimens and the progress of laparoscopic surgical techniques, the overall survival (OS) is still poor in most patients with advanced CRC [1]. Digestive cancer, especially CRC, is known to induce local inflammation according to cancer progression. Local inflammation 
Table 1. Clinical, pathological, and biochemical characteristics and PCT between cancer-specific non-survivors and survivors in all 277 patients with CRC

\begin{tabular}{lccr}
\hline & Non-survivors $(n=46)$ & Survivors $(n=231)$ & $p$ value \\
\hline Gender (male/female) & $33 / 13$ & $128 / 103$ & 0.0490 \\
Age, years old & $67 \pm 1.7$ & $68 \pm 0.7$ & 0.0493 \\
CEA, ng/mL & $287 \pm 211$ & $8.6 \pm 1.0$ & 0.0032 \\
CA19-9, U/mL & $172 \pm 82$ & $18.4 \pm 1.0$ & $<0.0001$ \\
PNI & $42.5 \pm 1.0$ & $45.5 \pm 0.4$ & 0.0049 \\
Preoperative PCT, ng/mL & $0(0-0.0575)$ & $0(0-0)$ & 0.0004 \\
PCT at postoperative day 1, ng/mL & $0.670(0.235-2.6175)$ & $0.215(0.07-0.7675)$ & 0.0003 \\
mGPS (0/1/2) & $30 / 5 / 11$ & $208 / 9 / 14$ & 0.0003 \\
Site of tumor (right side/left side) & $13 / 33$ & $59 / 172$ & 0.8568 \\
Tumor diameter, mm & $52.6 \pm 1.6$ & $39.7 \pm 1.6$ & 0.0007 \\
Differentiation of cancer (well, mod/others) & $43 / 3$ & $218 / 13$ & 0.8152 \\
TNM classification (stage 0/I/II/III/IV) & $0 / 1 / 5 / 15 / 25$ & $12 / 85 / 63 / 64 / 7$ & $<0.0001$ \\
Curative resection (CurA/B/C) & $20 / 3 / 23$ & $223 / 2 / 6$ & 0.0894 \\
POI (positive/negative) & $28 / 18$ & $198 / 33$ & 0.0003 \\
\hline
\end{tabular}

Data are expressed as mean \pm standard error or median (25-75 percentile). CRC, colorectal cancer; mGPS, modified Glasgow Prognostic Score; PNI, prognostic nutritional index; PCT, procalcitonin; POI, postoperative infectious complication.

in the tumor microenvironment augments angiogenesis, leukocyte accumulation, and fibrosis, which accelerates cancer progression [2]. In this concept, several systemic inflammation-related markers were demonstrated to predict cancer-specific prognosis, such as the C-reactive protein (CRP), the Glasgow Prognostic Score (GPS) [3], the neutrophil-to-lymphocyte ratio [4], and the prognostic nutritional index (PNI) [5]. A large population study from Proctor et al. [6] revealed that systemic inflammation-based scores, particularly, modified GPS (mGPS) and PNI, have a prognostic value in cancer, independent of tumor origin.

Procalcitonin (PCT) is a polypeptide consisting of 116 amino acids and is the precursor of calcitonin. Assicot et al. [7] first described the role of PCT under inflammatory conditions, especially sepsis and bacterial infections. Since then, it has been reported to be a useful marker for diagnosis of bacterial infections, septic conditions, and the severity of sepsis $[8,9]$. Recent studies have reported significant relationships between PCT and malignant tumors. Cotoi et al. [10] demonstrated that PCT is independently associated with the risk for cancer-specific mortality in apparently healthy men. Moreover, elevation of PCT is significantly associated with the incidence of colon cancer [10]. Herein, we assess the clinical and prognostic implication of preoperative PCT in CRC patients, comparing inflammation-based prognostic scores, such as $\mathrm{mGPS}$ and PNI.

PCT and Prognosis for Colorectal Cancer

\section{Materials and Methods}

\section{Patients}

We retrospectively reviewed clinical and laboratory data of 339 consecutive CRC patients who underwent surgical treatment between October 2010 and December 2014 at Shiga University of Medical Science Hospital (Shiga, Japan). Laboratory analyses of serum PCT, CRP, albumin, carcinoembryonic antigen (CEA), and CA19-9 were routinely performed before surgery. Timing of blood sampling is basically in the day before surgery or before induction of anesthesia. PCT was measured by Elecsys ${ }^{\circledR}$ Brahms PCT and Cobas $8000^{\circledR}$ (Roche Diagnostics Corporation, Tokyo, Japan; range $0.05-100 \mathrm{ng} / \mathrm{mL}$ ) [11]. The $\mathrm{mGPS}$ and PNI were evaluated as previously described $[5,6]$. Disease stages of CRC were defined according to the TNM Classification of Malignant Tumors 7th edition published from the UICC. Postoperative infectious complications (POIs) were defined according to the Centers for Disease Control and Prevention surveillance definition [12]. POI such as deep surgical site infection (SSI) and superficial SSI that were connected with the site of anastomotic leakage was counted as anastomotic leakage.

\section{Statistical Analysis}

Qualitative variables were indicated as numbers and compared with Fisher's exact test or $\chi^{2}$ test. Plausibility of normal distribution for continuous variables was evaluated by the one-sample ShapiroWilk test. Continuous variables with normal distribution are expressed as mean \pm standard error and were compared using Student $t$ tests. Continuous variables without normal distribution are expressed as median and quartiles/90 percentile, which were evaluated with Wilcoxon signed-rank test. The best cutoff value for continuous variables to determine cancer-specific OS and relapsefree survival (RFS) was calculated by receiver operating character- 


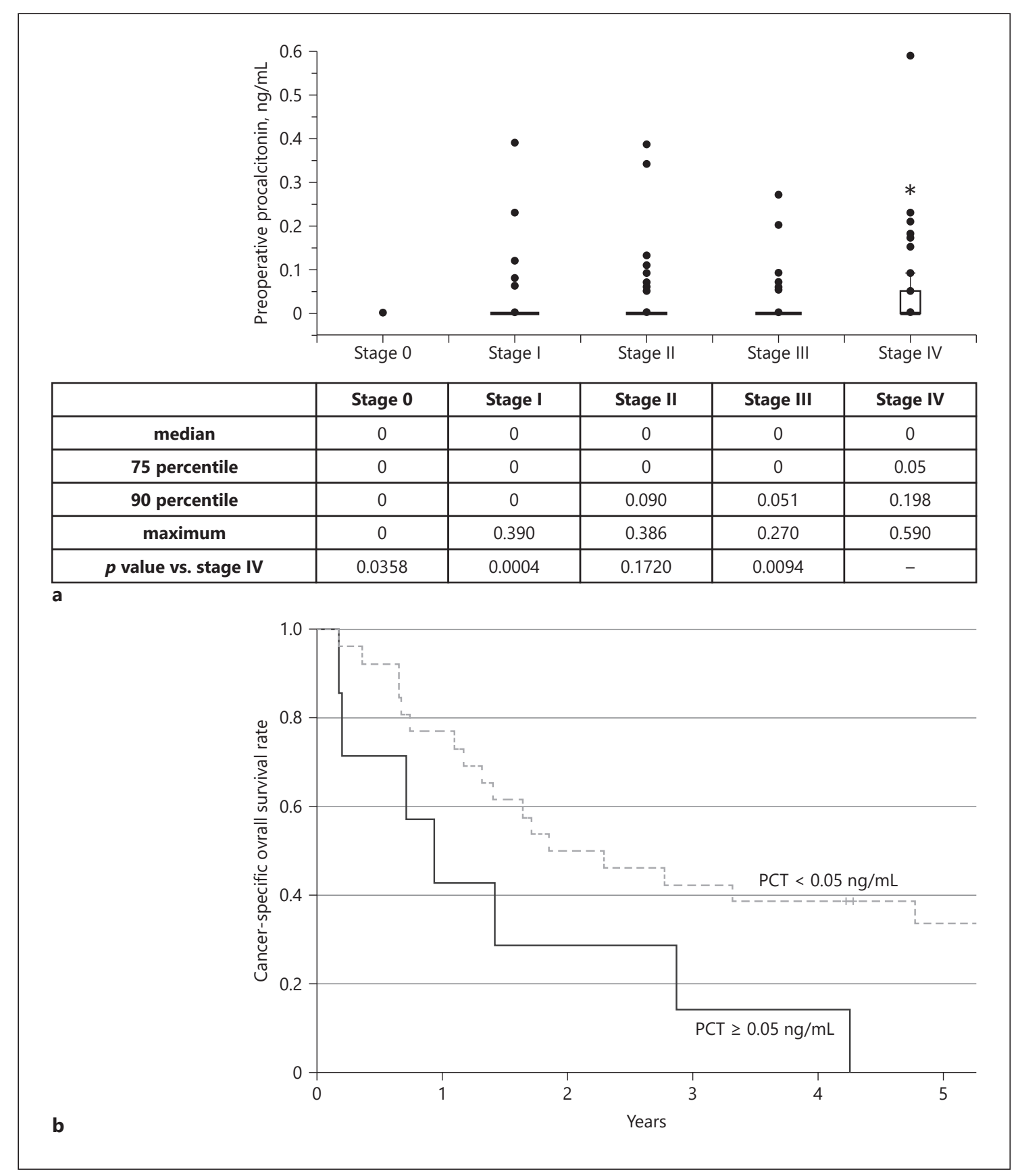

Fig. 1. The relation of PCT and cancer-prognosis in patients with Stage IV CRC. a Preoperative PCT levels divided by CRC staging. ${ }^{*} p<0.05$ versus Stage 0 , I, and III. b Cancer-specific OS in Stage IV CRC patients divided by PCT level. 3 years survival rate, PCT $\leq 0.05 \mathrm{ng} / \mathrm{mL} ; 42.3 \%$ versus PCT $>0.05 \mathrm{ng} / \mathrm{mL} ; 14.3 \%$, log-rank test $p=$ 0.0413. PCT, procalcitonin; CRC, colorectal cancer; OS, overall survival.

istic curve analysis. To examine the clinical significance of pathophysiological parameters on cancer-specific OS and RFS, survival analysis was performed by the Kaplan-Meier method. Hazard ratios with 95\% confidence intervals were calculated with univariate and multivariate analysis using the Cox proportional hazard mod- el to identify risk factors for cancer-specific OS and RFS. Statistical analysis was performed using JMP14 (SAS Institute Inc., Cary, NC, USA) and IBM SPSS ver. 25 (IBM Corp, Tokyo, Japan). A $p$ value $<0.05$ was considered statistically significant. 
Table 2. The relationship between clinical, pathologic, and biochemical characteristics and cancer-specific OS in 232 patients with stage I, II, and III CRC: univariate and multivariate analysis

\begin{tabular}{|c|c|c|c|c|c|}
\hline & & $\begin{array}{l}\text { Univariate } \\
\text { analysis HR (95\% CI) }\end{array}$ & $p$ value & $\begin{array}{l}\text { Multivariate } \\
\text { analysis HR (95\% CI) }\end{array}$ & $p$ value \\
\hline \multicolumn{6}{|l|}{ Gender } \\
\hline Female & $n=132$ & 1 & \multirow[t]{2}{*}{0.0393} & 1 & \multirow[t]{2}{*}{0.0311} \\
\hline Male & $n=100$ & $3.166(1.058-9.471)$ & & $3.360(1.117-10.11)$ & \\
\hline \multicolumn{6}{|l|}{ Age } \\
\hline$<70$ & $n=116$ & 1 & \multirow[t]{2}{*}{0.2676} & & \\
\hline$\geq 70$ & $n=116$ & $1.659(0.678-4.059)$ & & & \\
\hline \multicolumn{6}{|l|}{ Site of tumor } \\
\hline Left side & $n=175$ & 1 & \multirow[t]{2}{*}{0.3750} & & \\
\hline Right side & $n=57$ & $0.574(0.168-1.957)$ & & & \\
\hline \multicolumn{6}{|l|}{ Differentiation } \\
\hline Well, mod & $n=216$ & 1 & \multirow[t]{2}{*}{0.0551} & & \\
\hline Others & $n=16$ & $3.330(0.974-11.38)$ & & & \\
\hline \multicolumn{6}{|l|}{ Tumor diameter } \\
\hline$<38 \mathrm{~mm}$ & $n=126$ & 1 & \multirow[t]{2}{*}{0.0646} & & \\
\hline$\geq 38 \mathrm{~mm}$ & $n=106$ & $2.379(0.949-5.964)$ & & & \\
\hline \multicolumn{6}{|c|}{ TNM classification } \\
\hline Stage I, II & $n=154$ & 1 & \multirow[t]{2}{*}{0.0006} & 1 & \multirow[t]{2}{*}{0.0039} \\
\hline Stage III & $n=78$ & $5.908(2.147-16.25)$ & & $4.764(1.652-13.73)$ & \\
\hline \multicolumn{6}{|l|}{ Preoperative PCT } \\
\hline$<0.08 \mathrm{ng} / \mathrm{mL}$ & $n=217$ & 1 & \multirow[t]{2}{*}{0.0070} & 1 & \multirow[t]{2}{*}{0.0448} \\
\hline$\geq 0.08 \mathrm{ng} / \mathrm{mL}$ & $n=15$ & $4.542(1.512-13.64)$ & & $3.851(1.176-12.62)$ & \\
\hline \multicolumn{6}{|l|}{ CEA } \\
\hline$<7.0 \mathrm{ng} / \mathrm{mL}$ & $n=169$ & 1 & \multirow[t]{2}{*}{0.0025} & 1 & \multirow[t]{2}{*}{0.0843} \\
\hline$\geq 7.0 \mathrm{ng} / \mathrm{mL}$ & $n=63$ & $3.907(1.617-9.440)$ & & $2.296(0.894-5.897)$ & \\
\hline \multicolumn{6}{|l|}{ CA19-9 } \\
\hline$<24 \mathrm{U} / \mathrm{mL}$ & $n=178$ & 1 & \multirow[t]{2}{*}{0.0138} & 1 & \multirow[t]{2}{*}{0.3294} \\
\hline$\geq 24 \mathrm{U} / \mathrm{mL}$ & $n=54$ & $3.025(1.253-7.301)$ & & $1.601(0.622-4.124)$ & \\
\hline \multicolumn{6}{|l|}{ mGPS } \\
\hline 0,1 & $n=216$ & 1 & \multirow[t]{2}{*}{0.5001} & & \\
\hline 2 & $n=16$ & $1.653(0.383-7.128)$ & & & \\
\hline \multicolumn{6}{|c|}{ 20 } \\
\hline$\geq 45$ & $n=102$ & 1 & \multirow[t]{2}{*}{0.8522} & & \\
\hline$<45$ & $n=130$ & $1.087(0.450-2.624)$ & & & \\
\hline \multicolumn{6}{|l|}{ POI } \\
\hline Negative & $n=195$ & 1 & 0.0644 & & \\
\hline Positive & $n=37$ & $2.456(0.947-6.418)$ & & & \\
\hline
\end{tabular}

OS, overall survival; CRC, colorectal cancer; HR, hazard ratio; CI, confidence interval; mGPS, modified Glasgow Prognostic Score; PNI, prognostic nutritional index; PCT, procalcitonin; POI, postoperative infectious complication.

\section{Results}

\section{Patients Background}

Of 339 consecutive CRC patients, 34 patients had no PCT measurement before surgery. One patient died within 30 days after surgery. Six patients had infectious conditions before surgery. Twenty-one patients were excluded because of neoadjuvant chemotherapy and/or irradiation. Finally, 277 patients were analyzed in this study.
The median follow-up interval was 5.00 years in all patients (survivors: 5.05 years, cancer-specific death: 2.04 years). Thirty-six patients developed recurrence and $46 \mathrm{pa}-$ tients died due to recurrences or metastases of CRC. The distributions of gender, age, CEA, CA19-9, PNI, preoperative PCT, tumor diameter, TNM classification, curative resection, $\mathrm{mGPS}$, and POI were significantly associated with cancer-specific patients' mortality (Table 1). Fifty-one POIs in 48 patients took place: 19 superficial SSI, 11 anastomotic 
Table 3. The relationship between clinical, pathologic, and biochemical characteristics and cancer-specific RFS in 232 patients with stage I, II, and III CRC: univariate and multivariate analysis

\begin{tabular}{|c|c|c|c|c|c|}
\hline & & $\begin{array}{l}\text { Univariate analysis } \\
\mathrm{HR}(95 \% \mathrm{CI})\end{array}$ & $p$ value & $\begin{array}{l}\text { Multivariate analysis } \\
\text { HR (95\% CI) }\end{array}$ & $p$ value \\
\hline \multicolumn{6}{|l|}{ Gender } \\
\hline Female & $n=132$ & 1 & \multirow[t]{2}{*}{0.1365} & & \\
\hline Male & $n=100$ & $1.720(0.842-3.511)$ & & & \\
\hline \multicolumn{6}{|l|}{ Age } \\
\hline$<70$ & $n=116$ & 1 & \multirow[t]{2}{*}{0.7015} & & \\
\hline$\geq 70$ & $n=116$ & $1.138(0.587-2.209)$ & & & \\
\hline \multicolumn{6}{|l|}{ Site of tumor } \\
\hline Left side & $n=175$ & 1 & \multirow[t]{2}{*}{0.3440} & & \\
\hline Right side & $n=57$ & $0.654(0.271-1.576)$ & & & \\
\hline \multicolumn{6}{|l|}{ Differentiation } \\
\hline Well, mod & $n=216$ & 1 & \multirow[t]{2}{*}{0.1292} & & \\
\hline Others & $n=16$ & $2.241(0.790-6.356)$ & & & \\
\hline \multicolumn{6}{|l|}{ Tumor diameter } \\
\hline$<38 \mathrm{~mm}$ & $n=126$ & 1 & \multirow[t]{2}{*}{0.0093} & 1 & \multirow[t]{2}{*}{0.0997} \\
\hline$\geq 38 \mathrm{~mm}$ & $n=106$ & $2.526(1.256-5.078)$ & & $1.834(0.897-3.989)$ & \\
\hline \multicolumn{6}{|c|}{ TNM classification } \\
\hline Stage I, II & $n=154$ & 1 & \multirow[t]{2}{*}{$<0.0001$} & 1 & \multirow[t]{2}{*}{0.0005} \\
\hline Stage III & $n=78$ & $4.174(2.076-8.391)$ & & $3.543(1.743-7.203)$ & \\
\hline \multicolumn{6}{|l|}{ PCT } \\
\hline$<0.08 \mathrm{ng} / \mathrm{mL}$ & $n=217$ & 1 & \multirow[t]{2}{*}{0.1567} & & \\
\hline$\geq 0.08 \mathrm{ng} / \mathrm{mL}$ & $n=15$ & $2.123(0.749-6.018)$ & & & \\
\hline \multicolumn{6}{|l|}{ CEA } \\
\hline$<7.0 \mathrm{ng} / \mathrm{mL}$ & $n=169$ & 1 & \multirow[t]{2}{*}{0.0422} & 1 & \multirow[t]{2}{*}{0.3719} \\
\hline$\geq 7.0 \mathrm{ng} / \mathrm{mL}$ & $n=63$ & $2.017(1.025-3.971)$ & & $1.377(0.6824-2.778)$ & \\
\hline \multicolumn{6}{|l|}{ CA19-9 } \\
\hline$<24 \mathrm{U} / \mathrm{mL}$ & $n=178$ & 1 & \multirow[t]{2}{*}{0.0551} & & \\
\hline$\geq 24 \mathrm{U} / \mathrm{mL}$ & $n=54$ & $1.980(0.985-3.980)$ & & & \\
\hline \multicolumn{6}{|l|}{ mGPS } \\
\hline 0,1 & $n=216$ & 1 & \multirow[t]{2}{*}{0.2183} & & \\
\hline 2 & $n=16$ & $1.924(0.679-5.451)$ & & & \\
\hline \multicolumn{6}{|l|}{ PNI } \\
\hline$\geq 45$ & $n=102$ & 1 & \multirow[t]{2}{*}{0.7946} & & \\
\hline$<45$ & $n=130$ & $1.092(0.5617-2.124)$ & & & \\
\hline \multicolumn{6}{|l|}{ POI } \\
\hline Negative & $n=195$ & 1 & \multirow{2}{*}{0.0211} & 1 & \multirow[t]{2}{*}{0.0940} \\
\hline Positive & $n=37$ & $2.371(1.138-4.949)$ & & $1.892(0.890-3.989)$ & \\
\hline
\end{tabular}

RFS, relapse-free survival; CRC, colorectal cancer; HR, hazard ratio; CI, confidence interval; mGPS, modified Glasgow Prognostic Score; PNI, prognostic nutritional index; PCT, procalcitonin; POI, postoperative infectious complication.

leakages, 5 enteritis, 5 catheter-related blood stream infections, 3 intra-abdominal abscesses, 3 deep SSI, 2 pneumonias, 2 small intestinal perforations, and 1 urinary-tract infection. We observed overlapped POI in 3 patients. The PCT levels at POD1 in patients with POI (0.54 [0.17-2.41] $\mathrm{ng} / \mathrm{mL}$ ) was significantly higher than those in patients without POI (0.22 [0.07-0.89] ng/mL). Preoperative PCT levels according to tumor staging and cancer-related prognosis in patients with Stage 0 and IV CRC.
Preoperative PCT levels in Stage IV patients were significantly elevated compared to those in Stage 0, I, and III patients (Fig. 1a). Cancer-specific OS rate in Stage IV patients with preoperative PCT $\leq 0.05 \mathrm{ng} / \mathrm{mL}$ was significantly higher than those with preoperative PCT $>0.05 \mathrm{ng} /$ $\mathrm{mL}$ group (Fig. 1b). On the other hand, preoperative PCT were under detectable levels in Stage 0 patients. There was no recurrence and mortality in these patients during 5-year follow-up period. 
Preoperative PCT and Cancer-Related Prognosis in

232 Stage I-III Patients

We, therefore, analyzed the risk factors of cancer-specific OS in 232 Stage I-III patients. Gender, TNM classification, preoperative PCT, CEA, and CA19-9 were identified as significant risk factors for cancer-specific OS in these patients by univariate analysis. In the multivariate analysis, gender, TNM classification, and PCT were independently associated with cancer-specific OS in these patients (Table 2). The cancer-specific OS rate in these patients with PCT $\geq 0.08 \mathrm{ng} / \mathrm{mL}$ was significantly decreased compared with PCT $<0.08 \mathrm{ng} / \mathrm{mL}$ group (5-year survival rate with PCT $\geq 0.08 \mathrm{ng} / \mathrm{mL} ; 59.1 \%$ vs. with PCT $<0.08 \mathrm{ng} /$ $\mathrm{mL} ; 92.7 \%$, log-rank test $p=0.0031$ ).

Furthermore, we evaluated the risk factors for cancerspecific RFS in these patients. The univariate analysis revealed that tumor diameter, TNM classification, CEA, and POI were identified as significant risk factors for cancer-specific RFS. Finally, TNM classification was detected as an independent risk factor for cancer-specific RFS in these patients (Table 3 ).

\section{Discussion}

The measurement of PCT is commonly used in the world to assist in the diagnosis of bacterial infection. In the 2016 Surviving Sepsis Campaign guideline, it is suggested that measurement of PCT levels can also be used to support shortening the duration of antimicrobial therapy in septic patients [13]. We also found the significant elevation in PCT levels at POD1 in patients with POI; however, the diagnostic impact of PCT at POD1 for POI was lower than that of CRP at POD1, 3, and 7 in this study (data not shown) as previously discussed [14].

The significant relationship between preoperative PCT and malignant tumors was recently reported [10]. The elevated PCT levels are related to disease stage in solid cancer patients [15]. Other studies also reported that PCT level was an important prognostic factor for patients with hepatocellular carcinoma [16], neuroendocrine neoplasms of digestive system [17], and lung cancer [18]. Collectively, our finding seems to be consistent with recent findings related to PCT and malignant tumors.

Previous studies have reported the usefulness of the GPS for the prediction of postoperative mortality in CRC patients [19]. Therefore, we compared PCT with mGPS in terms of prognostic significance for cancer-specific OS in CRC patients in this study. Finally, we found that PCT but not $\mathrm{mGPS}$ was one of the significant risk factors for cancer-

PCT and Prognosis for Colorectal Cancer specific OS in Stage I-III patients by univariate and multivariate analysis, although we found statistically significant association with mGPS and cancer-specific OS/RFS in all Stage $0-I V$ patients (data not shown). The exclusion of incompetent 62 patients due to no PCT measurements, and so on before surgery may influence our findings in statistical analysis of mGPS for cancer-specific OS/RFS.

Preoperative PCT appeared to be associated with poor OS but not RFS in Stage I-III patients after surgery. There was no significant difference in therapeutic strategies, such as surgery and chemotherapy, after relapse of cancer depending on preoperative PCT; however, the period from detection of relapse to cancer-specific death was significantly shorter in high preoperative PCT patients than that in low preoperative PCT (data not shown). This rapid tumor progression after relapse of cancer observed in high preoperative PCT patients may be related to the increased systemic inflammatory condition in such patients since perioperative systemic inflammation and sepsis are recognized as a risk for the progression of CRC [20]. The increasing evidence also indicates that chronic inflammation plays a pivotal role in tumor development, as well as progression, metastasis, and resistance to chemotherapy [21].

The systemic PCT appeared to be produced in the liver and peripheral mononuclear cells under the influence of cytokines and endotoxin [22]. The recent study demonstrated that the traditional beneficial bacteria such as Lactobacillus and Bifidobacterium decreased significantly and the carcinogenic bacteria such as Enterobacteriaceae and Fusobacterium nucleatum were significantly increased, which was associated with gut mucosal barrier dysfunction in early-stage CRC patients with the increased levels of plasma endotoxin [23]. Furthermore, the detection of microbial DNA fragments in the blood of CRC patients was correlated with shorter survival [24]. These leakage of endotoxin and microbial fragments into the circulation accompanied with dysbiosis of the gut microbiome in CRC patients may be related to preoperative elevation of PCT observed in our study. The disease progression and prognosis in cancer patients are not only determined by the local characteristics of the tumor but also by the systemic host immune and inflammatory response; therefore, we believe that preoperative evaluation of inflammatory status measured by PCT especially detecting bacterial infection might have clinical impact compared to CRP, mGPS, and PNI for patients with CRC receiving surgery.

There are some limitations to this study. The first limitation is its retrospective and single-institutional characteristics and small sample size. Second, the mechanism of PCT elevation before surgery was not clarified in this 
study. To further understand the clinical relevance of preoperative PCT in CRC patients, a prospective study with large sample numbers is needed.

\section{Conclusion}

Our findings suggested that high preoperative PCT values in CRC patients appeared to be associated with poor OS but not RFS following surgical treatments.

\section{Statement of Ethics}

Informed consent was obtained from each patient prior to surgery. This study was performed in accordance with the Declaration of Helsinki and was approved by the human ethics review committee in Shiga University of Medical Science (Approved ID:29-028). The authors declare that they have no competing interests.

\section{Conflict of Interest Statement}

All authors declare that they have no possible conflicts of interest.

\section{Funding Sources}

This study was supported by a JSPS KAKENHI grant (No. 20K09005; Japan Grant-in-Aid for Scientific Research (C)).

\section{Author Contributions}

T.M., T.S., T.U., M.K., H.O., T.Y., H.I., S.K., E.M., Y.E., and M.T. analyzed and interpreted the patient data regarding the colorectal cancer. T.M. and T.S. were major contributors in writing the manuscript. All authors read and approved the final manuscript.

\section{References}

1 Brenner H, Kloor M, Pox CP. Colorectal cancer. Lancet. 2014;383(9927):1490-502.

2 Terzic J, Grivennikov S, Karin E, Karin M. Inflammation and colon cancer. Gastroenterology. 2010;138:2101-14 e2105.

3 McMillan DC, Canna K, McArdle CS. Systemic inflammatory response predicts survival following curative resection of colorectal cancer. Br J Surg. 2003;90(2):215-9.

4 Tanaka H, Muguruma K, Toyokawa T, Kubo N, Ohira M, Hirakawa K. Differential impact of the neutrophil-lymphocyte ratio on the survival of patients with stage IV gastric cancer. Dig Surg. 2014;31(4-5):327-33.

5 Kanda M, Fujii T, Kodera Y, Nagai S, Takeda S, Nakao A. Nutritional predictors of postoperative outcome in pancreatic cancer. $\mathrm{Br} \mathrm{J}$ Surg. 2011;98(2):268-74.

6 Proctor MJ, Morrison DS, Talwar D, Balmer SM, Fletcher CD, O'Reilly DS, et al. A comparison of inflammation-based prognostic scores in patients with cancer. A glasgow inflammation outcome study. Eur J Cancer. 2011;47(17):2633-41.

7 Assicot M, Gendrel D, Carsin H, Raymond J, Guilbaud J, Bohuon C. High serum procalcitonin concentrations in patients with sepsis and infection. Lancet. 1993;341(8844):515-8.

8 Iida $\mathrm{H}$, Maehira H, Mori H, Tani M. Serum procalcitonin as a predictor of infectious complications after pancreaticoduodenectomy: review of the literature and our experience. Surg Today. 2020 Feb;50(2):87-96.

9 Shimizu T, Obata T, Sonoda H, Akabori H, Miyake T, Yamamoto H, et al. Diagnostic potential of endotoxin scattering photometry for sepsis and septic shock. Shock. 2013;40(6):504-11.

10 Cotoi OS, Manjer J, Hedblad B, Engström G, Melander O, Schiopu A. Plasma procalcito- nin is associated with all-cause and cancer mortality in apparently healthy men: a prospective population-based study. BMC Med. 2013;11:180

11 Shimizu T, Hanasawa K, Sato K, Umeki M, Koga N, Naganuma $T$, et al. Perforation PMXTSGiSPwC: the clinical significance of serum procalcitonin levels following direct hemoperfusion with polymyxin B-immobilized fiber column in septic patients with colorectal perforation. Eur Surg Res. 2009;42: 109-17.

12 Horan TC, Andrus M, Dudeck MA. CDC/ NHSN surveillance definition of health careassociated infection and criteria for specific types of infections in the acute care setting. Am J Infect Control. 2008;36(5):309-32.

13 Rhodes A, Evans LE, Alhazzani W, Levy MM, Antonelli M, Ferrer R, et al. Surviving sepsis campaign: international guidelines for management of sepsis and septic shock: 2016. Intensive Care Med. 2017;43(3):304-77.

14 Reith HB, Mittelkötter U, Debus ES, Küssner C, Thiede A. Procalcitonin in early detection of postoperative complications. Dig Surg. 1998;15(3):260-5.

15 Matzaraki V, Alexandraki KI, Venetsanou K, Piperi C, Myrianthefs P, Malamos N, et al. Evaluation of serum procalcitonin and interleukin-6 levels as markers of liver metastasis. Clin Biochem. 2007;40(5-6):336-42.

16 Shen H, Zheng S, Chen R, Jin X, Xu X, Jing C, et al. Prognostic significance of serum procalcitonin in patients with unresectable hepatocellular carcinoma treated with transcatheter arterial chemoembolization: a retrospective analysis of 509 cases. Medicine. 2017;96(28):e7438.

17 Chen L, Zhang Y, Lin Y, Deng L, Feng S, Chen $\mathrm{M}$, et al. The role of elevated serum procalci- tonin in neuroendocrine neoplasms of digestive system. Clin Biochem. 2017;50:982-7.

18 Patout M, Salaün M, Brunel V, Bota S, Cauliez B, Thiberville L. Diagnostic and prognostic value of serum procalcitonin concentrations in primary lung cancers. Clin Biochem. 2014; 47(18):263-7.

19 Sugimoto K, Komiyama H, Kojima Y, Goto M, Tomiki Y, Sakamoto K. Glasgow prognostic score as a prognostic factor in patients undergoing curative surgery for colorectal cancer. Dig Surg. 2012;29(6):503-9.

20 Carroll GM, Burns GL, Petit JA, Walker MM, Mathe A, Smith SR, et al. Does postoperative inflammation or sepsis generate neutrophil extracellular traps that influence colorectal cancer progression? A systematic review. Surg Open Sci. 2020;2(2):57-69.

21 Liu J, Lin PC, Zhou BP. Inflammation fuels tumor progress and metastasis. Curr Pharm Des. 2015;21(21):3032-40.

22 Oberhoffer M, Stonans I, Russwurm S, Stonane E, Vogelsang H, Junker U, et al. Procalcitonin expression in human peripheral blood mononuclear cells and its modulation by lipopolysaccharides and sepsis-related cytokines in vitro. J Lab Clin Med. 1999;134(1): 49-55.

23 Liu X, Cheng Y, Shao L, Ling Z. Alterations of the predominant fecal microbiota and disruption of the gut mucosal barrier in patients with early-stage colorectal cancer. Biomed Res Int. 2020;2020:2948282.

24 Messaritakis I, Vogiatzoglou K, Tsantaki K, Ntretaki A, Sfakianaki M, Koulouridi A, et al. The prognostic value of the detection of microbial translocation in the blood of colorectal cancer patients. Cancers. 2020; 12(4):1058. 